\title{
The Recent Trademarking of Pi: A Troubling Precedent
}

\section{Jonathan M. Borwein and David H. Bailey}
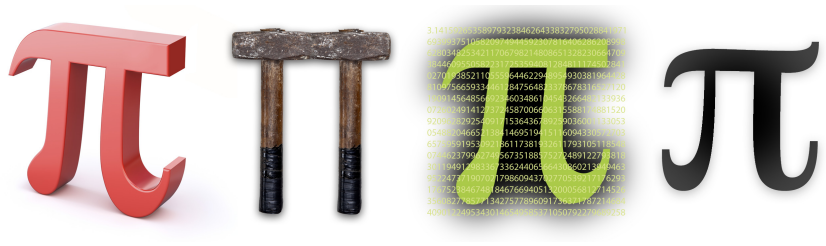

The many shapes of pi.

\section{Background}

Intellectual property law is complex and varies from jurisdiction to jurisdiction, but, roughly speaking, creative works can be copyrighted, while inventions and processes can be patented and brand names thence protected. In each case the intention is to protect the value of the owner's work or possession.

For the most part mathematics is excluded by the Berne Convention [1] of the World Intellectual Property Organization (WIPO) [12]. An unusual exception was the successful patenting of Gray codes in 1953 [3]. More usual was the carefully timed Pi Day 2012 dismissal [6] by a US judge of a copyright infringement suit regarding $\pi$, since " $\mathrm{Pi}$ is a noncopyrightable fact."

We mathematicians have largely ignored patents and, to the degree we care at all, have been more concerned about copyright as described in the work of the International Mathematical Union's Committee on Electronic Information and Communication (CEIC) [2]. ${ }^{1}$ But as the following story indicates, it may now be time for mathematicians to start paying attention to patenting.

Jonathan M. Borwein is laureate professor of mathematics at CARMA, University of Newcastle. His email address is jon . borwein@gmai 1 .com.

David H. Bailey is retired senior scientist at Lawrence Berkeley National Lab and research fellow at University of California, Davis. His email address is david@davi dhbai 1 ey.com.

DOI: http://dx.doi.org/10.1090/noti1172

${ }^{1}$ A decade ago the CEIC wrote at some length on copyright issues and was surprised at the relative paucity of good information available at the time.

\section{Pi Period ( $\pi$.)}

In January 2014 the U.S. Patent and Trademark Office granted Brooklyn artist Paul Ingrisano a trademark on his design "consisting of the Greek letter Pi, followed by a period." It should be noted here that there is nothing stylistic or in any way particular in Ingrisano's trademark-it is simply the standard Greek letter $\pi$ followed by a period. That's it $-\pi$ period. No one doubts the enormous value of Apple's partly eaten apple or MacDonald's arch. But $\pi$ period?

We live in an era of aggressive patent trolling by vulture patent firms [10]. There is a vast amount at stake. Think of the current smartphone patent wars and the sometimes successful patenting of life forms. Additionally, it is often cheaper for a firm to pay than go to court. A vague patent can be a "nice little earner," and thus even established firms such as Microsoft and Apple go patent trolling and successfully patent such generalities as "a method to enable...." Other firms are more willing to "open source" some of their intellectual property, such as, for example, Tesla's announcement [9] that it will open some of its patents in an attempt to help spur the electric automobile industry.

\section{What Happened Next?}

This is the disturbing part. To underscore that he means business, Ingrisano, through his lawyer, Ronald Millet, sent a letter to Zazzle.com, a $\pi$ novelty company, to "immediately cease and desist" their "unlawful" usage of their $\pi$ period trademark or "any confusingly similar trademark" and within 14 days:

(1) provide an accounting of all sales of any products containing their trademark;

(2) provide an inventory of all relevant products;

(3) disclose any other uses, electronic or print, that have been made of the trademark;

(4) provide an account of the date when the $\pi$ trademark was first incorporated into their products, a list of all known links to Zazzle's webpage, and a list of third parties who offer such products. 
The letter threatened attorney's fees and "treble money damages." The full text of the letter is available [4].

Implied in the letter is the plaintiff's position that "any confusingly similar trademark" includes the $\pi$ symbol itself, without the period, since none of the products offered by Zazzle features a $\pi$ followed by a period. Indeed, according to a report in Wired [13], Ingrisano's attorney, Millet, has asserted that many items for sale by Zazzle "clearly have a pi sign and look similar enough that folks out there might confuse it with products that my client also sells."

Zazzle responded by temporarily banning all garments featuring the $\pi$ symbol, which involved "thousands of products," according to the Wired report [13]. But two days later, after being flooded with complaints, Zazzle restored the products. Millet is consulting with Ingrisano as to their next step.

Along this line, it is amusing to note that a $\pi$ design is featured [5] by the Mathematical Association of America as a finalist for its 2014 MAA Annual T-Shirt Design Contest (and the design includes one formula that one of the present authors was instrumental in discovering). Will the MAA be challenged as well? Perhaps not, but we live in a very litigious world, and a given university or company lawyer may well decide discretion is the better part of valor and opt to keep their clients out of trouble by forbidding use. One of us had his former employer (Dalhousie) order him to desist from using the name of the institution on a bank account he had been advised to set up by his Dean for a research center.

\section{The Smiley Face}

This episode is reminiscent of a dispute over the "smiley face" between litigants Wal-Mart Stores and SmileyWorld, a London-based company that registered rights to the smiley face many years ago on behalf of Franklin Loufrani [7]. The dispute was finally settled in June 2011 under undisclosed (but likely quite expensive) terms [8].

Unlike the $\pi$ case, no one has argued that the smiley face has scientific significance! But the case does demonstrate that such disputes must be taken seriously. Moreover, the smiley face is a defined and recognizable image, and Loufrani explicitly makes no attempt to stop the use of it in email as plain text, such as :).

\section{Pi in Modern Mathematics and Science}

The $\pi$ period trademark, and the aggressive actions taken by the trademark holder, may seem amusing, though they are certainly unfortunate for Zazzle and its owners, employees, and customers. But much more is at stake here. If Ingrisano and his attorney prevail in their legal actions, this would mean, in effect, that anyone who uses the $\pi$ symbol in any context the holder views as encroaching would live under the threat that they might receive a similar "cease and desist" letter, with the threats of significant financial loss. This would be an unmitigated disaster for modern mathematics and science.

It is not the slightest exaggeration to say that $\pi$ is the most important irrational constant of modern mathematics. Each year, the $\pi$ symbol appears in thousands of published books and in tens (possibly hundreds) of thousands of technical papers-not just in books and papers related to geometry but also in fields as diverse as statistics and quantum physics.

In fact, the numerical value of $\pi$ (expressed in binary digits) is contained in every smartphone ever produced, since the computations performed to process wireless signals (using the fast Fourier transform) inherently involve $\pi . \pi$ appears in several guises in the equations of quantum physics and thus is central to semiconductor electronics. $\pi$ even arises in GPS technology, since the frequency of clock signals broadcast by GPS satellites must be adjusted according to the formulas of Einstein's general relativity, the equations of which involve $\pi$. The mind reels at the thought that the authors of every mathematical, scientific, or engineering paper that uses a $\pi$ symbol must live under a cloud of worry that they too might be accused of "trademark violation" by including $\pi$ symbols in their articles.

\section{What to Do?}

True, it would take quite a stretch of trademark law precedent before $\pi$ characters appearing in mathematical literature would be at peril. The $\Omega$ symbol has been used to promote watches for decades without litigation. The $\infty$ symbol has been used to promote automobiles without run-ins with mathematicians. The same is true for Yahoo's trademark, which is little more than a block Y, and Google's trademark, namely a capital G.

But even if legal hassles over $\pi$ in mathematical papers are an unreasonable worry, as the legal advice quoted below suggests, can we really not freely put $\pi$ on our pens, thumb drives, coffee cups, posters, and T-shirts?

For the same reason that $\pi$ is omnipresent in mathematical literature, it is also omnipresent in the larger cultural milieu of mathematics, and to place a legal cloud over the usage of $\pi$ on everyday novelty items and posters would seriously hamper the humanization of modern mathematics.

Also, if $\pi$ is placed under a cloud of trademark violation, what is next? The letter $e$, the base of natural logarithms? The summation sign $\Sigma$ (another 
Greek letter)? The integral sign $\int$ ? Should the American Mathematical Society or the International Mathematical Union trademark all mathematical symbols, including notation such as 5!, as logos and release them under a general public license? No precedent even remotely approaching this scenario should be tolerated.

A lawyer familiar with trademark law (see "Sidebar") has advised us that "the trademark registration for a symbol, such as a Greek letter, would never preclude normal use of the letter." But we wonder if he is being a tad bit optimistic. As the current case indicates, legal battles can, at the least, make life quite uncomfortable for those who would use mathematical notation in relatively innocent settings.

The best solution, in our view, is simply for the U.S. Patent and Trademark Office either to rescind trademarks such as the $\pi$ period trademark or, at the least, to very clearly rule that such trademarks do not extend beyond the actual registered combination on specific commercial products and to block any future attempts at trademarking mathematical symbols. There definitely are precedents for such action, including the June 2014 action by the U.S. Patent and Trademark Office to cancel the Washington Redskins' registration of their image, which was ruled as disparaging to Native Americans [11]. Surely the needs of the worldwide mathematical and scientific community to use standard notation free from trademark worries is an equally compelling justification. For such patent nullification to happen, the American Mathematical Society or some other body needs to take legal action.

\section{Sidebar: A Note on Trademark Law and Trademarks in General}

To be clear, the issue discussed in the article is a trademark matter, not a patent matter. Rights in trademarks are given for branding products and services, and they are a matter of commercial identity. The right of a trademark owner to exclude others from using a mark is granted only in respect of commercial activities, typically by field and geographical area. Exclusive rights in trademarks specifically do not extend to what is referred to as "ornamental use," that is, use not related to commercial activities in which the trademark is used for branding. The touchstone for determining infringement (violation) of rights in a trademark thus is the "likelihood" the use in question would confuse consumers about products (or services) of others with the trademark branded products (or services) of the trademark owner.

Thus, trademark rights in mathematical symbols do not have anything to do with their ordinary use in mathematics and publications on mathematics or any other "ornamental" use (ornamental in this context meaning anything other than commercial use of the mark for branding products or services offered commercially). Thus a trademark right in a mathematical symbol does not preclude its use for decorative purposes, other than as a brand. And a trademark owner in a mark involving a mathematical symbol would have to show likelihood of confusion due to the use of a mark to obtain relief. In other words, the scholarly use of mathematical symbols cannot be trademarked and cannot be held to infringe anyone's trademark rights.

It is easy enough to see this by analogy to familiar trademarks on letters, words, as well as on specific mathematical symbols, illustrated by the following examples. Neither the Yahoo trademark, which is little more than the letter "Y", nor the Google trademark, which is little more than the letter " $G$ ", has any bearing on free use of these letters in writing. The same applies to words that are trademarks, such as "Guess" (clothing), "Coke" (Coca-Cola), and "Apple" (computer and software products), to name just a few. And the trademarks that utilize Greek letters, such as Infinity/Infiniti (using both the word and the letter) for loudspeakers and automobiles (by different owners) and Omega (using the symbol) for both watches and electronic metering equipment (also different owners), do not affect the use of these symbols outside their specific association with the company's products and certainly not their use in mathematics.

The trademark referred to in this article is for the use of pi period for branding certain types of clothing. (The registration not only limits use of the mark to clothing, it also specifically excludes its use on a number of particular types of clothing such as basketball-related articles.) The mark has no bearing on any use of pi period outside this limited commercial application of the mark to clothing products to indicate their "brand" (the origin of the goods, in trademark parlance). The registration and trademark rights in the mark pi period does not bear at all on decorative uses of pi period or its use in mathematics.

Indeed, this is only one of many trademarks involving the symbol for pi or the word pi. Registration of these marks are orthogonal to one another, and none of them bears on uses of the word or the symbol in any context other than for branding commercial products or services. They have nothing to do with the use of pi in ordinary mathematics publications, discussion, problem solving, etc.

The demand letter noted in the article would, in the ordinary course of affairs, be sent by the trademark holder to another entity thought to be 
using the pi period mark (or something confusingly similar) in association with the sale of the same type of clothing. The owner of the mark is not entitled to assert rights in it against purely ornamental users, such as those who use pi (word or symbol) in an ornamental (decorative) way.

While the foregoing discussion centers on the trademark owner, the ultimate purpose of the trademark system is to protect the consumer and the public by ensuring that Apple computers actually are Apples, the drink in the Coca-Cola bottle really is Coke, Lipitor really is atorvastatin from Pfizer, Teslas are made by Tesla, and Chevys by GM. In other words, it is designed to ensure that branded products and services are those of the brand owner, not the products or services of other providers.

The law attempts to optimize rules affecting partially defined, dynamic, multiparametric, nonlinear systems, and every legal regime has limitations and imperfections. The trademark system is no exception. Abuses can and do occur. In crafting the law, we have to balance the protection to be afforded to trademark holders against countervailing public interests, including the potential for abuse of the sort discussed in the article. Whether the level of such misuse at present warrants alterations in the law should be assessed dispassionately by looking at the frequency of abuse and its cost, on the one hand, and, should it seem to warrant changing the law, by the effects and burdens each proposed change would likely engender on trademark holders generally and on the public.

As the authors note, there is considerable concern currently being voiced in the US about unwarranted assertion of patent rights by socalled patent "trolls," and Congress is considering a variety of legislation to address fraudulent assertion of patent rights. The issue should not arise for trademarks in the same way, because trademark holders must actually use their marks in commerce, thus giving them some real value, whereas patent owners do not have to practice their patents. Furthermore, trademark rights are tightly defined: by the mark itself, by the registered uses and geographical area, and by the definition of infringement, which requires likelihood of commercial confusion. Thus there is reason to be optimistic that trademark abuse will not become a substantial issue that requires alterations to the law, but, if the need arises, all three branches of government will respond (as they are doing with regard to patents).

-Larry S. Millstein, Ph.D. ${ }^{2}$

\footnotetext{
${ }^{2}$ Larry S. Millstein has been an IP lawyer for over twenty years and is a partner in the law firm of Millen, White, Zelano \& Branigan, PC. His Ph.D. is in chemistry/molecular biology.
}

\section{References}

[1] Berne Convention, Wikipedia, viewed June 22, 2014, http://en.wikipedia.org/wiki/ Berne_Convention

[2] Committee on Electronic Information and Communication, International Mathematical Union, Recommendations on information and communication, viewed June 22, 2014, http://www. mathunion.org/fileadmin/CEIC/Publications/ Copyright_Recommendations.pdf.

[3] RoberT W. DORAN, The Gray Code, Journal of Universal Computer Science 3, no. 11 (2007), 1573-1597; http://www.jucs.org/ jucs_13_11/the_gray_code/jucs_13_11_1573_ 1597_doran.pdf.

[4] Letter from Ronald Millet to Zazzle, Inc., May 16, 2014, http://www. documentcloud. org/documents/1175624-zazzle-pi-trademarkpetter.htmp.

[5] 2014 MAA Annual T-shirt Design Contest, viewed June 22, 2014, http://www.maa.org/ membership/maa-tshirt-contest.

[6] STEPHEN ORNES, US judge rules that you can't copyright pi, New Scientist, March 16, 2012, http://www. newscientist.com/article/dn21597us-judge-rules-that-you-cant-copyright-pi. html.

[7] ThOmas Crampton, Smiley face is serious to company, The New York Times, July 5, 2006, http://www.nytimes.com/2006/07/05/ business/wor7dbusiness/05smiley.htm7.

[8] Abigail Rubenstein, Wal-Mart settles trademark fight over smiley face logo, Law360, June 16, 2011, http://www. 1aw360.com/articles/251976/wa1mart-settles-trademark-fight-over-smileyface-1ogo.

[9] JERRY Hirsch and TIFFANY Hsu, Elon Musk opens up Tesla patents; it "isn't entirely altruistic," The Los Angeles Times, June 12, 2014, http://www. 1atimes.com/business/autos/ 1a-fi-hy-elon-musk-opens-tesla-patents20140612-story.htm?.

[10] Patent troll, Wikipedia, viewed June 22, 2014, http://en.wikipedia.org/wiki/Patent_ tro11.

[11] KEN BELSON and EDWARD WyATT, Redskins lose ruling on trademarks, but fight isn't over, The New York Times, June 18, 2014, http://www. nytimes.com/2014/06/19/sports/ footba11/us-patent-office-cancels-redskinstrademark-registration.htm 1

[12] World Intellectual Property Organization, viewed June 22, 2014, http://www.wipo.int/portal/en/.

[13] Kevin Poulsen, Man trademarks Pi, tries to cut out geeky T-shirt designers, Wired, June 2, 2014, http://www.wi red.co.uk/news/archive/2014-06/ 02/pi-trademark-usa 